\title{
On ecological slope protection technology of highway construction in Tibet
}

\author{
Meiling Li, Ying Yang*, Shihong Wu, Gang Xu \\ Tianjin Research Institute for Water Transport Engineering, M.O.T, Tianjin, 300456, China
}

\begin{abstract}
The study of highway ecological slope protection in the Tibet Autonomous Region of my country is still in its infancy due to factors such as climate and topography. This article introduces the main ecological slope protection technology and its application scope of Tibet highway, and analyzes the ecological slope protection technology from the perspective of the environmental characteristics of various areas in Tibet. The application in slope protection of highways in Tibet explores the existing problems and puts forward the suggestion that ecological slope protection needs to be combined with engineering slope protection. With the application and promotion of new technologies and techniques for ecological restoration and the gradual improvement of highway engineering construction techniques, the application of highway slope protection in Tibet will become increasingly perfect.
\end{abstract}

\section{Foreword}

Tibet is the main body of the Qinghai-Tibet Plateau. It has a high terrain and special geography. It is known as the "Roof of the World" and "The Third Pole of the Earth". It is the source of rivers in my country and Asia, and is a sensitive area of climate change in Asia even the northern hemisphere. It is an important national ecological security barrier and plays an irreplaceable role in climate regulation, water conservation and soil and water conservation, and biodiversity protection. Protecting Tibet's ecological environment is of great significance for promoting the sustainable development of the Qinghai-Tibet Plateau, advancing the construction of national ecological civilization, and promoting global ecological protection. Transportation is an important basic, leading, strategic industry and service industry of the Tibet Autonomous Region's national economy. It can greatly ease the bottleneck constraints of infrastructure in Tibet and provide strong support for the long-term economic and social development and long-term stability of Tibet. Highways are Tibet's most important means of transportation and the lifeblood of its economic development. It is of great significance to comprehensively building a well-off society, realizing sustainable development, promoting ethnic unity and social stability, and maintaining the unity of the motherland and national security.

- Road construction will change the ecological environment of the areas along the route. In addition, the construction of roads requires soil to fill embankments, and excavation of hills to form road cuts, which will inevitably destroy the original vegetation, destroy the natural balance of the soil, and cause slope instability.
Soil erosion. In view of the fragile characteristics of the ecological environment in Tibet, the applicability and limitations of the ecological slope protection technology in Tibet highway construction are analyzed through the investigation and summary of the ecological slope protection technology of Tibet highway.

\section{Research progress of ecological slope protection at home and abroad}

Developed countries attach great importance to ecological and environmental protection in road construction. In the 1930s and 1940s, the United States realized the importance of protecting ecological balance and began to restore vegetation on highway slopes. By the early 1950s, U.S. law required ecological restoration for new highways. Since the 1960s, with the large-scale construction of highways, the United States, Japan, and some developed countries and regions in Europe have incorporated ecological protection and restoration measures into highway construction. After long-term research and practice, the highway slope ecological restoration technology has gradually developed and improved, and new greening technologies such as spray seeding technology have been widely used in slope stability, soil erosion prevention, and vegetation restoration[1]. Japan improved the traditional spraying support method earlier, combining protection and greening. In 1976, the company took the lead in developing the thick-layer matrix spray slope protection technology and created a spray greening method. Spray greening technology has been continuously improved and perfected in Japan, and has become the most widely used ecological slope protection technology in Japan[2].

\footnotetext{
*Corresponding author's e-mail: yangyinggis@foxmail.com
} 
In addition, many scholars have also studied the influence of plants on the stability of slopes, and believe that plant roots have a reinforcing effect on slopes, and fibrous roots are more conducive to soil reinforcement and shear strength improvement than large roots. In recent years, my country's highway construction has made great progress. In the past, the protection of highway slopes was mainly based on simple engineering protection techniques, such as mortar masonry stones, dry masonry stones, and shotcrete. With the improvement of people's environmental awareness, more and more attention is paid to the ecological protection of highway slopes, and the comprehensive protection

Table 1. Main application of slope ecological protection technology at home and abroad and its scope of application

\begin{tabular}{cc}
\hline Type & Specific method or technique \\
\hline $\begin{array}{c}\text { Planting grass (trees) for seeding hole sowing, OH liquid grass } \\
\text { slope protection } \\
\text { planting, stone frame grass planting, hollow } \\
\text { six-sided brick grass planting, turf paving, row } \\
\text { planting vetiver, shrub slope protection, } \\
\text { grass-shrub slope protection, combined tree an } \\
\text { shrub slope protection }\end{array}$ \\
After paving regular hexagonal concrete frame \\
bricks on the trimmed side slope to form a \\
honeycomb grid, paving the grid with planting \\
soil, and then planting or planting grass in the \\
brick frame as a side slope protection measure
\end{tabular}

Vegetative zone

Lay the plant belt with seeds on the slope, fix it, and then properly maintain it

Vegetation type greening concrete technology, vegetation concrete slope protection greening technology

Hydraulic spraying technology, foreign soil spraying technology, spraying mixed planting technology

Greening net, three-dimensional vegetation net,

Geotechnical material planting grass for slope protection

Vertical greening slope protection

\section{Ecological Overview of Tibet}

As part of the highest level of terrain in my country, the Tibet Plateau is not only high in terrain, but also complex and diverse. The terrain of the plateau slopes from northwest to southeast, and the altitude gradually decreases from an average of $5000 \mathrm{~m}$ to about $4000 \mathrm{~m}$. The edge of the plateau is surrounded by high mountains and deep canyons. The inner surface of the plateau is based on the vast plateau surface, which is composed of large landform units such as plateaus, mountains, lakes, and basins. Basins and mountains are distributed alternately, forming the network structure characteristics technology of slopes has been developed unprecedentedly. Our country's ecological slope tection technology is mainly practiced and innovated wet spraying, sprayed soil spraying, and geogrid The application are shown in Table 1. These new logical slope protection technology has been promoted and applied in highway engineering. geonet, geocell, etc. combined with grass planting and slope protection

Climbing or hanging plants
Scope of application

Slow and low various soil slopes, severely weathered rock layers and soft rock slopes with poor fading effect, and the slope itself is stable

It is mostly used for the protection of fill slopes. The construction is simple, the appearance is neat, the appearance is beautiful and generous, it has the dual effects of slope protection and greening, and the project cost is moderate

It is mostly suitable for soil slopes with gentle slopes. The construction is simple, labor-saving, time-saving, easy to maintain, the seeds are not easy to lose, and the slope protection effect is good

Slope ratios less than 1:0.75, rock slopes and concrete slopes, high-steep slopes with slope ratios of $1: 1$ to $1: 0.15$

Road, railway, urban construction slope protection, the rock is moderately weathered, the slope is basically stable, the slope ratio is 1:1 1:0.75, mostly used for rock slopes steeper than 1:0.75

Design stable upper and lower slopes, especially upper slopes with poor soil and lower slopes filled with soil and rock; slopes of highways and dams

Rock slopes, built masonry slope protection and concrete slopes of plateau topography. Wide valleys, plateaus and basins are distributed in the network of mountains.

- The climate and weather in Tibet are unique and complex due to the influence of topography, landforms and atmospheric circulation. The climate is generally cold and dry in the northwest and warm and humid in the southeast. The distribution of precipitation in Tibet is quite different, with precipitation decreasing from the southeast of the plateau to the northwest. Under the alternate control of the winter westerly wind and the summer southwest monsoon, the difference between the dry season and the rainy season in Tibet is very obvious. Generally, the dry season is from October to April of the following year; the rainy season is from May to 
September, and the rainfall generally accounts for about $90 \%$ of the annual rainfall.

- The grassland ecosystem, especially the alpine grassland ecosystem, is the most distinctive ecosystem in Tibet. The forest ecosystem is the ecosystem with the highest biological productivity and the richest biodiversity in Tibet's ecosystem. It not only occupies a non-important position in Tibet and the whole country.

- The Tibet Autonomous Region has a vast territory, obvious topographical changes, complex topography, significant horizontal and vertical climatic differentiation, and very complex habitat changes. The environmental problems caused by road construction in different regions are also different.

\section{Application of Ecological Slope Protection Technology in Tibet Highway Construction}

With the application and promotion of new technologies and new technologies for ecological restoration in my country and the gradual improvement of highway engineering construction technology, the application of ecological slope protection technology in highway construction in Tibet is also gradually improving, focusing on vegetation ecological protection and supplemented by masonry engineering protection.

- According to the method of combining engineering plants, multi-level technical measures combining engineering and plants, such as skeleton turf, roadbed platform planting grass (transplanting turf), and turf drainage plant measures, are used to realize roadbed slope protection.

\subsection{Nagqu Plateau Mountain Alpine Shrub Meadow Area, Qiangtang Plateau Lake Basin Alpine Grassland Area}

The landform of Nagqu area is dominated by plateau hills and flat land. The climate belongs to the semi-arid monsoon climate zone of the plateau sub-frigid zone. The climate is cold, the air is thin, the four seasons are unclear, winter is longer than summer, and the weather is windy and snowy. Natural vegetation restoration is more difficult. Generally, the original turf within the highway construction area is stripped and maintained, and the slope is restored after the construction is completed for ecological protection of the slope.

- Before the construction of the project, the original ground meadow turf shall be shoveled up by dividing and shoveling, evenly stripped, properly planted and protected, and used for the transplantation and restoration of the roadbed slope turf. The mellow soil on the other ground surface is also stripped and stored as spare soil for covering the surface of the construction ground.

- For the road sections where vegetation is difficult to grow, retain the roadbed within the construction area and the surface vegetation where the construction vehicle passes by, transplant it section by section, and store it together with humus soil ex-situ and fake plants. After the roadbed is formed, cover it to the side of the completed roadbed Slope surface.

- In areas where there is a lack of resources in the meadow layer and suitable conditions, the measures of cement grid + sowing local suitable grass seeds are adopted for slope protection, and local species are selected, such as Stipa purpurea, Elymus nutans, and Kobresia alpine. , Carex Qingzang, Artemisia frigida, Bluegrass and Saussurea etc.

\subsection{Southern Tibet alpine valley shrub grassland area}

The high valleys of southern Tibet have high altitudes, dry and cold climate, fragile ecosystems, and difficult natural vegetation restoration. Vegetation protection is mainly based on sowing grass and planting shrubs. The process often uses arch and diamond frame protection, anchor frame beam protection, etc. Grass species often use bluegrass, slugging grass, oxtropis, and Peganum harmala. Part of the alpine meadow distribution area also uses native turf to stick slopes. Before subgrade construction, the surface soil and turf are stripped and temporarily stacked intact. After the subgrade is completed, the surface soil and turf are covered on the side slope of the subgrade or the leveled material yard.

\subsection{Coniferous forest area in high mountains and deep valleys in eastern Tibet}

The mountainous terrain of the southeastern Tibet plateau is complex and the climate conditions are also diverse. The tropical mountain areas south of Baizelin, Jiluo, and Walong have a humid monsoon climate. The annual average temperature is above $18-20^{\circ} \mathrm{C}$, with abundant heat and abundant rainfall, plants can grow throughout the year. The vegetation protection of mountain road slopes in the mountainous monsoon forests and evergreen broad-leaved forests in the southern wing of the Eastern Himalayas often adopts the method of mixed planting of shrubs and herbs. The cold-season turf plants are mainly tall fescue, red fescue and mature grass, and the warm-season turf plants are mainly bermudagrass and pseudograss. The cutting method is used to select korshinski, amorpha, seabuckthorn, Slope protection shrubs such as red willow, lespedeza, and sloping willow are planted.

\subsection{Ali the desert region}

The main ecological system in the desert area of Alishan is desert grassland. The climate is arid, the ecosystem is very fragile, soil erosion is serious, the ability to resist interference is poor, and the ecological environment is highly sensitive. For road sections where it is difficult to naturally restore vegetation on the side slope, cover the original surface soil on the side slope and sow droughtand cold-resistant grass seeds for restoration. 


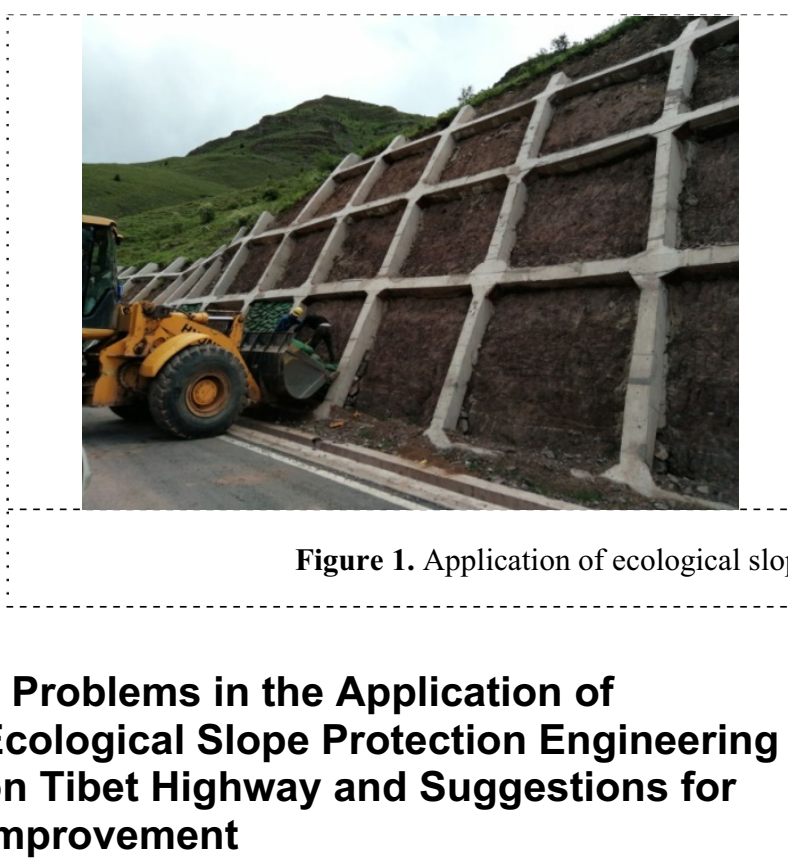

5.1Problems existing in the application of ecological slope protection engineering on Tibet highway

\subsubsection{Environmental protection awareness needs to be strengthened in the process of Tibet highway construction}

Since the 18th National Congress of the Communist Party of China, the Party Central Committee with Comrade Xi Jinping at its core has taken the construction of ecological civilization as an important part of the overall plan for promoting the "five in one" overall layout and the coordinated promotion of the "four comprehensive" strategic layout, and has carried out a series of fundamental, Innovative and long-term work, put forward a series of new ideas, new ideas and strategies. At the National Ecological Environmental Protection Conference held in Beijing on May 18, 2018, General Secretary Xi Jinping further clearly stated that the construction of ecological civilization is a fundamental plan for the sustainable development of the Chinese nation. Green water and green mountains are invaluable. Ecological civilization construction and green development have become a major development strategy at the national level and a basic criterion for promoting the healthy and sustainable development of various industries and fields.

- The high-cold and high-altitude area where the Tibet Highway Project is located is sensitive and fragile, with various types of ecosystems and many ecologically sensitive areas. However, the construction unit will not pay enough attention to ecological protection due to factors such as construction period and investment during the construction process. Insufficient ecological restoration of slopes results in low vegetation survival rate and soil erosion.

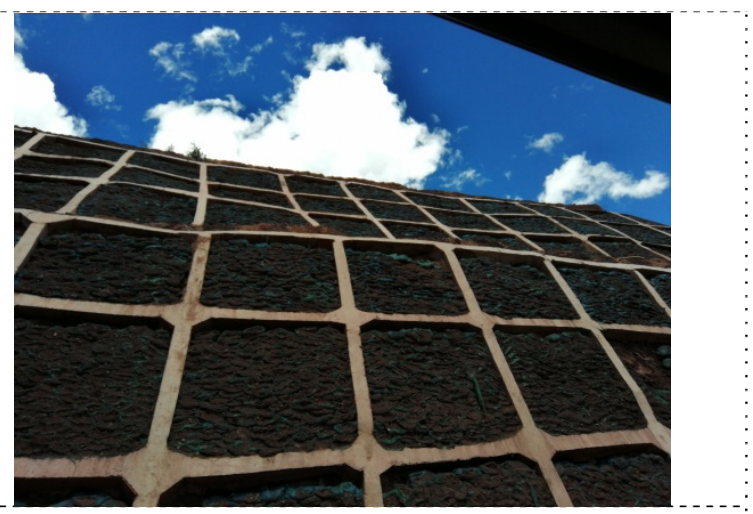

\subsubsection{Low vegetation survival rate in slope protection}

Tibet is located on the Qinghai-Tibet Plateau, with diverse terrain and complex climate. The mountainous tropical rain forest, monsoon forest ecological zone in southeastern Tibet, the semi-humid evergreen broad-leaved forest and dark coniferous forest ecological zone in the high mountains and deep valleys of eastern Tibet, etc. The low-mountain plain of the border decreases as the altitude rises to the north. The temperature below $1000 \mathrm{~m}$ has the characteristics of tropical climate, and the temperature above $1000 \mathrm{~m}$ decreases with the increase of altitude. Subtropical, temperate, frigid and alpine icy and snowy climates appear in sequence. In the subtropical and temperate zone, the effect of vegetation restoration is better and the maintenance cost is lower. However, areas such as the northern Qiangtang Plateau desert grassland ecological subregion and the Alishan temperate arid desert ecological region have low precipitation, fragile ecological environment, severe land desertification, low vegetation survival rate and high maintenance costs.

- Moreover, because the highway construction is a linear project, it often passes through multiple different climatic zones, and the single ecological slope protection technology is not conducive to adapting to different climates, and the effect of vegetation restoration on different road sections is also different.

\subsubsection{The extension of plant roots may cause cracks in the soil}

Ecological slope protection technology has played a role in gradually restoring the natural ecology and beautifying the environment, but it also has its limitations. For example, the extension of vegetation roots creates fissures in the soil, increases the permeability of the soil, is easy to increase precipitation infiltration, optimizes the recharge environment of groundwater, promotes the deep water and rock chemistry of the slope, and endangers the stability of the slope; The root depth of the anchorage is still unable to control the deeper sliding of the slope. If there is no stable rock and soil layer within the root extension range, its effect will not be obvious. If it encounters heavy wind and rain, it will easily pull out. 
Therefore, the ecological slope protection technology should be combined with engineering measures in the application, and the advantages of both should be used to ensure the stability of the slope, and play the role of vegetation restoration and beautification of the environment.

\subsection{Some Suggestions in the Application of Ecological Slope Protection Engineering on Tibet Highway}

\subsubsection{Strengthen the awareness of ecological protection in highway construction in Tibet}

For highway construction projects in ecologically fragile areas, environmental problems do not have to wait for the discovery of "sickness" to be remedied, but must be avoided through continuous optimization and design before the problem occurs. In the early design stage, the design unit is required to fully consider environmental protection factors, consider the environmental rationality of the route direction and control points, fully consider the terrain and geological conditions along the line and protect the ecological environment, and use the existing road subgrade as much as possible to reduce the disturbance to the side slope; The horizontal and vertical design of the route should be adapted to local conditions and coordinated with topographical conditions to reduce the amount of work; pay attention to the site selection and verification of temporary construction sites such as construction camps, borrow pits, and spoil yards, especially selecting sand and gravel yards as far as possible on the river beach, Wasteland without plants, and strictly control the number of installations, protect the original natural ecology to the greatest extent, and reduce the interference to the ecosystem.

- The construction unit shall fully grasp the environmental protection requirements in the design documents, and comprehensively consider the environmental conditions, project characteristics, process connection, construction technology and other factors, prepare the "Project Construction Environmental Protection Organization Plan" when the project starts, and formulate feasible implementation plans and implementation rules. Fully identify and analyze the project implementation environment and the environmentally sensitive areas such as nature reserves, forest parks, scenic spots, and drinking water sources within the project's impact area, and fully understand the relationship between the project and sensitive areas and the corresponding protection measures and requirements, and formulate Practical construction protection measures.

\subsubsection{Pay attention to local conditions and post-maintenance of ecological slope protection}

The terrain of Tibet is complex. As a linear project, highways pass through different areas and have different climatic conditions. Therefore, according to different areas, different terrains, different climate conditions, and different ecosystems, they are designed separately in combination with specific conditions. The design needs to be more detailed The suitability of the ecological slope protection scheme and the survival rate of vegetation. The ecological slope protection project is very fragile for a period of time after construction and before it grows up. It is mainly manifested in poor resistance to rain erosion and the possibility of vegetation growth failure. At the same time, ecological protection projects are often limited by construction time and lack suitable conditions. Vegetation and skilled workers, etc., these are the problems that must be solved in the application of ecological slope protection technology in highway slope protection. After completing the ecological slope protection project, the construction unit should pay attention to vegetation maintenance and increase the survival rate of vegetation.

\section{Conclusion}

This paper introduces in detail the current main application of slope ecological protection technology at home and abroad and its scope of application, and analyzes the application of ecological slope protection technology in Tibet highway slope protection from the perspective of the environmental characteristics of various regions in Tibet, and draws the following conclusions:

- The greatest value of the Qinghai-Tibet Plateau lies in ecology, the greatest responsibility lies in ecology, and the greatest potential lies in ecology. Adhering to ecological protection first, ecological slope protection is one of the important strategies for sustainable development in Tibet's highway construction projects.

- As the main body of the Qinghai-Tibet Plateau, Tibet has complex topography and geomorphology, diverse climates, and different regions with different suitability of ecological slope protection technology. The application of ecological slope protection technology in Tibet also has certain limitations. Actual engineering construction should adapt to local conditions to increase the survival rate of vegetation.

- In the process of highway construction in Tibet, it is necessary to strengthen the awareness of ecological protection, further strengthen the research of ecological slope protection technology, and pay attention to the later maintenance.

\section{Acknowledgements}

This work was supported in the part by the central level, scientific research institutes for basic R \&D special foundation (Grants Nos. KJFZJJ190204)

\section{References}

1. Li.H.F, Lu.X.S,JiangY.L. (2006)The Progress of Studies on the Technology of Side Slopes Restoration of Expressway [J].Sichuan Caoyuan, 2: 34-38. 
2. Zhang.X. (2016) Summary of Research on Ecological Restoration of Highway Slope in my country $[\mathrm{J}]$. Resource Conservation and Environmental Protection, No.172(03):85.

3. Zhao.J.W, Lu.J.G,(2006)Wang.R.H.The application effect of seven kinds of ecological slope protection on highway slope[J].Highway, 1: 201-204.

4. Zhou.D.P, Zhang.J.Y.(2003) Engineering technology of vegetation slope protection[M]. People's Communications Press, Beijing.

5. Wang.Y, Jiang.Y.L, Cui.P, Chen.X.P.(2006)Slope Ecological Protection Technology in Lufeng Section of Anchu Expressway[J].Soil and Water Conservation Research, 13(1): 139-141.

6. Wang.W.S, Yang.X.H, Xie.Y.L.(2005)Slope protection mechanism of highway slope plants[J].Journal of Chang'an University: Natural Science Edition, 25(4): 26-30.

7. Ou.Y.F, Wang.H.L, Wang.G, Wang.Q.H.(2007) Research on Vegetation Restoration of Ecological Slope Protection of Highway in the Loess Plateau Area[J]. Journal of Wuhan University of Technology, No.174(09): 162-166.

8. Zhuo.M.N, Li.D.Q, Zheng.Y.J. (2006)Study on Soil and Water Conservation Ef fect of Bioengineering Techniques for Slope Protection in Highway[J]. Journal of Soil and Water Conservation, 20,164-167. 